Alice Favaro

\title{
Voces efímeras: \\ el drama de la migración transfronteriza en México
}

Palabras claves: migrantes, subalternidad, trata tráfico, frontera

DOI: 10.4312 /ars.13.2.64-77

Detenido del lado mexicano del río Bravo, sentía el miedo de todos y el odio del otro lado. Iba a cruzar de todos modos.

(Carlos Fuentes)

Dicen, señora -vibró la voz-, que las cárceles de Texas están llenas de mexicanos; pero no dicen, señora, que esos mexicanos, tus hijos, no son delincuentes, que si han cruzado el río es para trabajar, para buscar honradamente el pan para sus hijos, porque tú sabes, señora, que los mexicanos no somos ladrones.

(González de la Garza)

La frontera entre México y Estados Unidos permite plantear una reflexión sobre la cuestión identitaria y los cambios socioculturales en ambos países. Esta frontera, una de las más largas del mundo con sus 3175 kilómetros de longitud, podría asociarse a la imagen de una herida abierta, una ruptura, un surco. Pero la franja fronteriza que comparten los dos estados, en realidad comprende una vasta área heterogénea no sólo desde el punto de vista físico y geográfico sino también social, económico y cultural, donde se produce el fenómeno del «ambiente fronterizo» (Martínez, 1994, 10) definido por Martínez como la totalidad de características y procesos que separan las fronteras de otras regiones del país dentro de las cuales acontecen interacciones, conflictos, negociaciones trasnacionales y étnicas. Por estas razones, no se puede considerar una sola frontera sino muchas fronteras, en las que estas identidades fronterizas transmigran, cruzando clandestinamente. Es la ciudad de Tijuana la que representa el cruce fronterizo internacional -incluyendo la migración legal e ilegal- del mayor movimiento humano en el mundo (Lomeli, 2012, 132). La frontera «telúrica, porosa, vibrante» (Rincones, 2004, 62) es ella misma representación de la otredad y el lugar de aparición del sujeto subalterno, zona de conflicto, compenetración, transgresión, hibridez cultural y contraposiciones.

La construcción de la imagen de frontera que se ha desarrollado a partir de los «Border Studies» o «Estudios Fronterizos», ha cobrado vida en distintas formas a través de los estudios de los numerosos críticos que se han ocupado del tema. Una de 
las exponentes más elocuentes, quizá, es Gloria Anzaldúa con Borderlands/La Frontera. The New Mestiza (1987), que ha contribuido a ampliar la visión sobre la frontera cual espacio cultural de gente mestiza, como si se tratara de un tercer país intermedio. Cabe recordar también La frontera de cristal: una novela en nueve cuentos (1995) de Carlos Fuentes, en que la frontera se percibe como "cicatriz abierta». Sin embargo, en estas dos interpretaciones de la frontera, hay que subrayar una diferencia entre la interpretación de los dos escritores: si Fuentes la considera como un espacio poroso y un extremo de México y su identidad mexicana donde se manifiesta lo más lejano de la mexicanidad «degenerando y diluyéndose a tal punto de ser irreconciliable» (Lomeli, 2012, 135), Anzaldua se concentra en el lugar del enfrentamiento entre las dos culturas en que acontecieron procesos de asimilación y adopción de las cualidades de una y de otra hasta que ambas resultasen ajenas.

La antropología también se ha ocupado del concepto de frontera; algunos ejemplos son los estudios de Arjun Appadurai, Néstor García Canclini y Michael Kearney a través de la antropología del espacio fronterizo, bien resumido en el artículo de Isabel G. Gamero Cabrera «Los límites del concepto de frontera en distintas teorías antropológicas posmodernas» (2015). Si Appadurai en Modernity at Large (1996), habla de un nuevo espacio global «rizomático» (Appadurai, 1996, 29), retomando la expresión de Deleuze, que se caracteriza por la «desterritorialización del espacio, la heterogeneidad cultural y el transnacionalismo» (Gamero Cabrera, 2015, 82), García Canclini, en su Culturas híbridas (2001), reflexiona sobre la pérdida de la relación que tradicionalmente se establece entre un espacio geográfico y una cultura concreta, delimitación que en el presente resulta imposible ya que el tránsito de flujos migratorios y movimientos interculturales está en aumento. Por último, Kearney destaca las dificultades en identificar una frontera concreta que puede, en cambio, considerarse como un espacio fluido y poroso continuamente traspasable. Por lo tanto, la frontera tendría, según el antropólogo estadounidense, una naturaleza indeterminada e imposible de categorizar con los conceptos tradicionales y el espacio fronterizo sería: «Una línea sin anchura [...] una zona social y cultural de amplitud indeterminada y se podría decir que corre profundamente desde México hasta Canadá» (Kearney, 2003, 55). Así que, tanto la antropología como la crítica literaria se revelan disciplinas teóricas que no disponen de las categorías adecuadas para describir una realidad que está en mutación constante, fluida y cambiante, «borrosa e inasible», en que las zonas fronterizas se tienen que analizar, según las palabras de Valencia, como:

Territorios-puerta, backdoor cities, donde confluyen de la misma manera y simultáneamente lo indeseable y lo deseable, hibridando estas características y haciendo difícil la aplicación de una axiología tradicional para su 
conceptualización, creando una especie de ruptura escatológica desde la cual se las concibe como autófagas y siniestras (Valencia, 2010, 123).

Entonces las innumerables interpretaciones que trazan la imagen de frontera que se desarrolla a través de una multitud de representaciones, configuraciones y conceptualizaciones, han evolucionado en el tiempo dentro de una gran variedad de marcos históricos y sociales. De hecho, según las palabras de Remón-Raillard, «La frontera es el nuevo sitio de construcción de un imaginario identitario» (RemónRaillard, 2013, 2). De la realidad plural, compleja y problemática de los espacios fronterizos donde acontecen choques, encuentros y fusiones, surge un tipo de relato ficcional en el que se narra para dar sentido a lo que ocurre.

La propuesta de aproximación al concepto de frontera desde lo literario permite la narración de una realidad concreta ficcionalizada donde es indisoluble la relación entre ficción (la novela) y crónica (el testimonio), y donde hay que plantearse qué separa el texto ficcional y la novela documental o testimonial, del mero testimonio. Citando a Pardo Fernández:

Literatura y metaliteratura, lo que se suele leer sobre la frontera entre México y Estados Unidos, se conforma como texto novelístico que trasgrede sus límites y reflexiona sobre la idea de qué más se puede decir, qué más se puede escribir cuando tantos mueren (Pardo Fernández, 2013, 176).

De hecho los discursos ficcionales sobre la migración son un fenómeno complejo que toma en cuenta muchos factores y que está relacionado con lo social, lo ideológico, con el poder y la miseria, la «idealización del sueño americano de vida y la pérdida de las raíces» (ibidem). Dentro del concepto de literatura testimonial, ${ }^{1}$ se ubican diferentes subgéneros según el énfasis que los autores ponen en el aspecto ficcional o social, y se distinguen por el tipo de tratamiento reservado a las fuentes. En esta definición general están presentes tanto los hechos relatados como acontecieron como los elementos artísticos y subjetivos (Súarez Gómez, 2011). Según la definición de Gustavo García, la literatura testimonial podría definirse como un género que «por medio de la literaturización de un hecho social previo, estructura una unidad discursiva híbrida y subordinada a los intereses ideológicos de sus productores» (García, 2003, 50). También John Beverley, ofrece una definición de testimonio como de:

1 Como afirma Suárez Gómez, no hay un consenso sobre la denominación del género discursivo: «Algunos autores hablan de discurso testimonial, novela política, novela testimonio, novela documental, literatura testimonial, narración testimonial, ficciones documentales, narrativa de no ficción, literatura de resistencia, o simplemente testimonio; entre otras denominaciones que indican que hay un universo testimonial con claras diferencias entre cada subgénero. La diversidad en las conceptualizaciones radica en las múltiples perspectivas de análisis que se pueden utilizar para clasificar y en las diversas técnicas que pueden ser utilizadas para narrar. Pese a las diferencias, entre todos esos conceptos puede hallarse cierta identidad entre contenidos temáticos, estilo y composición -aunque con diversas articulaciones» (Suárez Gómez, 2011, 63). 
una narración con la extensión de una novela corta, en forma de libro o panfleto (esto es, impresa y no acústica), contada en primera persona por un narrador que es también el verdadero protagonista o testigo de los sucesos relatados, y cuya unidad narrativa es por lo general una 'vida' o una experiencia significativa de vida (Beverley, 2010, 22).

El surgimiento de las novelas «híbridas» que se alejan de la literatura testimonial considerada como discurso que relata un hecho social previo a través de la voz de los testigos de los acontecimientos (Suárez Gómez, 2016, 35-38), y comprenden otros géneros literarios, permite presentar las realidades sociales y políticas cuánto más actuales. Son precisamente estos tipos de novelas «híbridas que [...] 'liberan' al relato autobiográfico del testimonio de su función legal y lo lleva a la posibilidad de construir un relato aún desde el horror y la vulnerabilidad» (Peña Iguarán, 2018, 148), y permiten transformar de manera crítica la realidad y reflexionar sobre cuál es la necesidad de la narrativa actual hoy. Como afirma Pardo Fernández: «De lo que se trata, al fin, es de la raíz, el origen, el afán de constituir (descubrir, recuperar) la identidad. Toda la narrativa sobre la migración, sobre la frontera como herida y sobre los mexicanos como pueblo, se conforma a partir de la idea de la raíz al aire, sin sustento: el desarraigo» (Pardo Fernández, 2013, 175-176).

\section{Las tierras arrasadas}

Estas novelas sobre la frontera se insertan en el marco de una tendencia literaria que se mimetiza con el espacio al que remiten y que tiene la urgencia de representar la realidad cómo es. Es precisamente lo que Beatriz Sarlo define como «realismo etnográfico» (Sarlo, 2006), es decir la representación documental de la realidad en la ficción, o «el desplazamiento, la distancia» (Piglia, 2009, 91), del cual habla Piglia cuando afirma que hay que salir del centro para dejar hablar al otro, desde el margen. Es decir, el considerar la novela como documento de los intercambios sociales dentro de la marginalidad donde la literatura asume por sí misma el rasgo documental de representación de los temas culturales del presente. En los últimos años estas novelas que relatan la realidad de la frontera mexicana han sido muchas y todas se focalizan sobre el tema central de la violencia, sobre todo a partir de 1995, después de la intensificación de la agresividad debido a las políticas migratorias (Pardo Fernández, 2012, 9-17).

Las tierras arrasadas (2015), ganadora del IX Premio Iberoamericano de Novela Elena Poniatowska en 2016, es una obra compleja; en esta ocasión propongo un breve análisis del texto para que se comprenda por qué puede considerarse como una novela fronteriza, no sólo por el tema que trata sino también por el género literario 
que se coloca entre varios géneros, precisamente entre la crónica y la ficción que se enuncia desde la frontera. Este tipo de literatura, que se ocupa de la marginalidad y de la subalternidad, tiene algunos elementos recurrentes entre los cuales se nota una tendencia en emplear un lenguaje bajo y coloquial que emula la lengua callejera para identificarse y mimetizarse con la realidad que relata e intenta reconstruir. Además, el estilo pierde su estética para dejar espacio al montaje de las imágenes; de hecho, es como si la novela estuviera compuesta por un conjunto de imágenes extremadamente reales para alcanzar al lector con más fuerza (Pardo Fernández, 2013, 13).

En su novela E. Monge (Ciudad de México, 1978), politólogo y escritor que ya ha publicado relatos, crónicas y reseñas literarias, describe un apocalíptico panorama fronterizo, desolado y violento, donde el lector desciende al infierno en que viven los migrantes centroamericanos, secuestrados en el cruce de la frontera entre México y Estados Unidos. La frontera, que aparece como lugar problemático y zona violenta, es al mismo tiempo creadora de historias, donde se relata la cuestión compleja de la industria migratoria en el contexto mexicano, controlada, en buena medida, por el crimen organizado. De hecho, los secuestros de migrantes en los trenes que van al norte -extorsionados, maltratados, violados y matados si no pueden pagar por su liberación- acontecen cotidianamente. Solamente en 2010 este asunto de urgencia humanitaria alcanzó la presencia mediática internacional por primera vez cuando, en San Fernando (Tamaulipas), se descubrieron los cuerpos de 72 migrantes, en la mayoría centroamericanos, torturados y asesinados (Peña Iguarán, 2018, 143).

El texto está compuesto por numerosas voces, historias y niveles de narración que se superponen y se intercambian constantemente: la voz de los migrantespersonajes propuesta a través de los testimonios de archivo de migrantes de América Central, la voz del narrador y unos versos de la Divina Comedia; todo eso se mezcla con la historia de amor de una pareja de traficantes que se desarrolla a través del nivel ficcional de la novela.

La narración, que se articula mediante un narrador omnisciente, relata la atrocidad y la barbarie en que viven los migrantes, más allá de lo que es humanamente decible y concebible. Precisamente como en el Infierno de Dante, la naturaleza, en esta zona fronteriza, es violenta y cruel, ella misma un personaje, una especie de monstruo que traga al hombre sin piedad, como se puede leer en algunas de estas citas: «[...] oyen entonces los sonidos que la selva exhala en su hora negra: suenan los gritos de los monos aulladores, en el arroyo cantan las chicharras escondidas en la hierba» (Monge, 2012, 16), «[...] ruge la bestia de estas latitudes y la selva enmudece un breve instante» (ivi, 30), «[...] la veloz metamorfosis de la selva» (ivi, 31), «[...] el zumbido de la selva incorpora a su delirio nuevos ruidos» (ivi, 33). La naturaleza, por 
lo tanto, es un elemento fundamental en la construcción de un escenario demoníaco donde la selva es la protagonista, aquella misma selva oscura ultraterrenal, símbolo de la vida pecaminosa en que se encuentra el protagonista de la Divina Comedia. La misma jungla divide en dos las tierras arrasadas y está poblada de las almas de los difuntos y de los cuerpos de los migrantes: «El viento que recorre la sierra, mientras Estela aprieta aún más el abrazo que a sí misma se está dando, arrecia arrancándole a las piedras los sonidos y las voces de los seres que hace años habitaron este sitio y que hoy son solamente polvo» (ivi, 160). No obstante, está poblada también de bestias e insectos que oyen el reclamo de la muerte e invaden el espacio en que se mueve el ser humano para llegar a tiempo a devorar los cuerpos y las plantas que tienen vida propia: «los helechos que escupieron a la sombra [...], constreñidos por las raíces de la higuera siempre hambrienta» (ivi, 261-263).

\section{Estela y Epitafio}

En esta naturaleza maligna en medio de la selva mexicana donde resuenan las voces de las almas que han habitado los mismos lugares, se mueven los protagonistas: Estela y Epitafio, una pareja que vive al margen de la ley. Estos traficantes de cuerpos comandan, a su vez, una banda de traficantes de migrantes. A pesar de lo que hacen y de la manera totalmente deshumana en que actúan, los dos tienen una historia de amor que constituye la principal estructura narrativa de la novela y que los aleja, por momentos, de la bestialidad que los caracteriza. Los dos simbolizan en sí la fealdad, la ferocidad y la falta de escrúpulos, aunque también la imposibilidad de redención de su propia condición; de hecho, de verdugos se convertirán en víctimas del mismo sistema en el que se mueven y trabajan, víctimas de la traición y de la venganza por parte de los otros compañeros.

Otro papel significativo en la narración está desarrollado por el cura Padre Nicho, jefe de Estela y Epitafio, que dirige el orfanato El Paraíso, donde se conocieron de pequeños. Aquí, en esta auténtica fábrica de futuros asesinos, donde se cuidan a los niños abandonados por los padres o secuestrados a los migrantes, los chicos están marcados a fuego y adiestrados para cumplir crímenes de todo tipo y, una vez adultos, entrar en la criminalidad organizada. Tanto Estela como Epitafio tienen un pasado violento y están traumatizados por el recuerdo de la infancia en el orfanato y por el abandono de los padres. En la banda de criminales que dirigen, cada miembro tiene un apodo que se refiere a la muerte y al rito fúnebre: Osaria, Ausencia, Sepulcro, Cementeria, Sepelio, Hipogeo, Mauselo. Estos apodos no solo remiten a la tradición mexicana del culto de los muertos -donde también es inmediata la referencia literaria a las obras de Octavio Paz y a las de Juan Rulfo- sino que se refieren también a la tarea 
que tienen de transbordar los cuerpos de las víctimas, cuyas almas ya están muertas, contribuyendo a hacer del texto una «alegoría de la necro-escritura» (Peña Iguarán, $2018,144)$.

Junto con ellos hay otros personajes siniestros, que aparecen en la novela como guardianes del umbral: las guías que traicionan a los migrantes entregándolos a los traficantes, especies de monstruos iletrados, los militares corruptos y dos viejos hermanos desguazadores de cadáveres, cuya tarea es descuartizar y quemar los cuerpos de los migrantes rebeldes, incómodos e inútiles.

La historia, que se transforma y modela continuamente, sigue las acciones de estos "personajes-máquina» (ivi, 143) que cambian a menudo sus nombres, rebautizados por el narrador, según lo que hacen o lo que sienten, como si fueran víctimas, ellos mismos, de un proceso de des-subjetivización: "Oigosololoquequiero", «Laciegadeldesierto», «ElquequieretantoaEstela», «LaqueadoraaEpitafio», escritos todos en una única palabra. Con este recurso narrativo, los personajes se convierten en lo que hacen: tienen que ser eficientes y se accionan como anestesiados. En la realidad en que se mueven no hay redención, salvación y absolución de los pecados para nadie, ni la posibilidad de modificar el propio destino, porque la violencia los ha marcado inexorablemente a todos desde pequeños.

\section{Existencias quebradas}

La voz que más fuerza tiene en la novela de Monge es precisamente la voz de los sin voz: los migrantes. Descritos como un conjunto de cuerpos sin nombre, despojados de su identidad y dignidad, reducidos a ser mera mano de obra, máquinas para trabajar, violados y torturados, estas existencias quebradas son mercancía. Sobre estos futuros esclavos del sistema corrupto y del capitalismo, reclutados en las guerras de los narcos, en los burdeles, en el tráfico de seres humanos, se desata la violencia más truculenta y sus cuerpos y sus vidas se convierten en valor de intercambio monetario y transnacional (Valencia, 2010, 123).

Sin embargo, estos hombres y estas mujeres, reducidos a nada más que carne y huesos, no tienen nombre, pero sí tienen voz. Como en el coro de una tragedia griega, el lector puede oír el lamento de las víctimas y las distintas voces que forman el coro. Son muchas voces débiles que se expresan y que constituyen los testimonios auténticos de los migrantes supervivientes del cruce. Así, la compleja estructura narrativa que constituye la novela es el resultado de años de investigaciones, trabajo de campo y consulta a innumerables fuentes por parte del autor, mezclados con referencias alegóricas y metaliterarias que configuran la historia ficcional. Como se escribe al final 
de la novela, el autor ha utilizado informaciones procedentes de la Comisión Nacional e Interamericana de los Derechos Humanos, de Amnistía Internacional, de la Casa del Migrante y del Albergue Hermanos en el Camino.

Los extractos de las declaraciones de los migrantes, que interrumpen la narración por breves líneas como si fueran fragmentos de una memoria que duele y que grita para escupir el horror sufrido, se distinguen del resto de las voces de la narración porque están escritas en letra cursiva, en primera persona y con una métrica diferente de la que se utiliza en el texto, acercándose aún más a las características del coro griego, como se puede leer en la siguiente cita:

Nos metieron en la casa que apestaba a cosa muerta... nos volvieron a golpear y a quemar... "el que se mueva lo vamos a matar»... nos pidieron nuestros números, de nuestras familias...les exigían diez mil dólares... se reían de ellos y nosotros... nomás por eso hablaban... sabían que no obtendrían nada (Monge, 2012, 78).

Estas personas, que huyen de la miseria de sus historias y que quieren borrar el pasado, son las primeras víctimas del mito del bienestar del primer mundo, transformados en mercancía absoluta por el capitalismo.

En los abismos infernales en que se ha abandonado toda esperanza y que no hay posibilidad de redención, la corrupción, como un virus, ha contagiado todo el país: las autoridades, el ejército y la iglesia. En una especie de danza macabra, bailan víctimas y verdugos, y las mismas víctimas se convierten en verdugos cuando se encuentran ante situaciones en las que, si intentan escapar del horror y rebelarse a lo que los traficantes los obligan a hacer -es decir, a masacrar a sus compañeros-, se convierten en victimarios ellos mismos; porque no hay posibilidad de huida y la propia vida siempre vale más que la vida de los otros. Los sin nombre, traicionados por quienes los guían y aniquilados a través de la extrema violencia a la que están sometidos, también asumen distintos apodos según el tipo de violencia sufrida o la degeneración, que el lector sigue, hacia la pérdida de la propia identidad: «aquellosquecruzaronlasfronteras [...], las sincuerpo [...], los sinnombre que llegaron de otra tierra [...], las sinalma [...], los sinDios que vienen de otras patrias [...], las sinvoz [...], los sintiempo [...], los sinalma que nacieron más allá de las fronteras» (ivi, 111).

A las voces efímeras de los «sin voces» se contraponen otras citas, también en cursiva, de algunos versos pertenecientes al Infierno de la Divina Comedia, que constituyen la voz de otro coro, y que puntúan el texto creando un tejido narrativo cuyos hilos se mezclan continuamente con la ficción y los testimonios de los individuos que cayeron en las redes de los traficantes de cuerpos. Como se puede leer en el texto: 
Como cuando la niebla se disipa y la vista reconstruye la figura de aquello que el vapor sólo promete, los que vienen de otras patrias pero no de otras lenguas reconocen la canción que están cantando encima de ellos y es así como comprenden que habrán de abandonar toda esperanza (ivi, 60).

Aquí, las fuentes, a pesar de que aparentemente no tienen nada que ver entre ellas, dialogan y se compenetran hasta llegar a ser casi indiscernibles y construir un texto que tiene una fuerza lírica notable y un dramatismo que nunca resulta patético.

El texto se compone entonces de una estructura narrativa compleja con tres intertextos: la historia de amor de los traficantes, los fragmentos de los testimonios de los migrantes, que en paralelo acompañan el relato principal, y las citas de la Divina Comedia que contribuyen a dramatizar la situación y exasperar la concienciación de la imposibilidad de salvación. Además, se puede añadir un cuarto intertexto compuesto por los nombres dados a todos los personajes por parte de la voz narradora.

El estilo de Monge, la prosa descarnada y el ritmo cadencioso contribuyen a crear un texto híbrido, una obra que evoca la solemnidad y la conmemoración religiosa. El lenguaje, que se parece a la crónica y está contaminado con la jerga, no economiza en la descripción de las escenas de violencia extrema, contadas por el narrador distanciado e imparcial incluso cuando relata la conducta de los traficantes. La lengua está subvertida, como si indicara la imposibilidad de representar la violencia humana con la escritura tradicional y fuese necesario reinventar el lenguaje.

Este texto profundamente realista y testimonial, narrado con una violencia a veces insostenible, definido por el mismo autor como «la historia del último holocausto de la especie» (Monge, 2012, 341), es una novela necesaria para arrojar luz a la cara oculta de la humanidad: los desarraigados de la historia; toda aquella humanidad a la deriva, sujetos marginados que la sociedad, por no querer hacerse cargo, prefiere ignorar. Este relato plantea una reflexión necesaria sobre cómo seguir viviendo después de conocer el horror del que es capaz el hombre y cómo es posible seguir 'estando mirando' la muerte de los migrantes de cada rincón del planeta.

La novela, que surge de múltiples trazos, es una narración que traspasa la frontera de un solo género literario, dando lugar a una obra híbrida, una historia ficcional de denuncia y testimonio donde se invierte la normal contraposición entre víctimas y victimarios. El texto, que crea un relato sobre la frontera y desde la frontera, está enriquecido justamente por la elección del género híbrido utilizado, con una narración que se sitúa en el encuentro entre ficción y relato testimonial, ella misma en la frontera entre géneros literarios. Como afirma Ginzburg: 
Contra la tendencia del escepticismo posmoderno a difuminar la frontera entre narraciones de ficción y narraciones históricas, en nombre del elemento constructivo que las pone en pie de igualdad, proponía considerar el vínculo entre unas y otras como una disputa por la representación de la realidad. Pero antes que una guerra de trincheras, planteaba la hipótesis de un conflicto hecho de desafíos, préstamos recíprocos, hibridaciones. (Ginzburg, 2010, 12)

La propuesta de aproximación al concepto de frontera desde lo literario permite el desarrollo de un tipo de narración situada entre la crónica y lo ficcional que no puede considerarse ni literatura testimonial ni literatura de ficción. Esta narración, infringiendo los límites de diferentes géneros literarios, se revela como el género híbrido ideal para la construcción de una imagen de frontera relatada desde los márgenes, que se mimetiza con la realidad que describe, pero que tiene que construir un modo para comunicar lo incomunicable, que no se encuentra en un solo modo de expresarse. La ficción, que trasciende la historia y la trasforma a través de la imaginación, emplea un estilo eficaz que llega inmediatamente al lector, constituido por una pluralidad de voces y géneros literarios. El resultado es un relato que, dando voz a los que habitan el margen, y desde diferentes perspectivas desde las cuales se desarrolla el hilo narrativo, crea un texto que deja el lector desquiciado por el horror y por la conciencia de haber formado parte de la narración de una memoria colectiva perteneciente a su contemporaneidad.

\section{Bibliografía}

Appadurai, A., Modernity at large, Minneapolis 1996.

Beverley, J., Testimonio: sobre la política de la verdad, México 2010.

Gamero Cabrera, I. G., Los límites del concepto de frontera en distintas teorías antropológicas posmodernas, Cinta de moebio. Revista de Epistemología de Ciencias Sociales 52, 2015, pp. 79-90.

García Canclini, N., Culturas híbridas. Estrategias para entrar y salir de la modernidad, México 2001.

García, G., La literatura testimonial latinoamericana. (Re) presentación y (auto) construcción del sujeto subalterno, Madrid 2003.

Ginzburg, C., El hilo y las huellas. Lo verdadero, lo falso, lo ficticio, Buenos Aires 2010.

Jiménez Estrada, C., De la novela-testimonio como género, Íkala. Revista de lenguaje y cultura 5, Medellín 1998, pp. 85-94.

Kearney, M., Fronteras y límites del estado y el yo al final del imperio, Alteridades 25, 2003, pp. 47-62. 
Lomeli, F. A., La frontera entre México y Estados Unidos: transgresiones y convergencias en textos transfronterizos, Iberoamericana 46, 2012, pp. 129-144.

Martínez, O. J., Border People: Life and society in the U. S. - México Borderlands, Tucson 1994.

Monge, E., Las tierras arrasadas, México 2015.

Pardo Fernández, R., La novela negra de la frontera: violencia y subversión, Mitologías hoy 6, 2012, pp. 9-17.

Pardo Fernández, R., La ficción narrativa de la frontera: El río Bravo en tres novelas mexicanas, Frontera Norte 49, 2013, pp. 157-178.

Peña Iguarán, A., Vidas residuales: el arte en los tiempos de guerra. Las tierras arrasdas (2015) de Emiliano Monge, Mitologías hoy 17, 2018, pp. 135-149.

Piglia, R., Tres propuestas para el próximo milenio (y cinco dificultades), Pasajes. Revista de pensamiento contemporáneo 28, 2009, pp. 81-93.

Remón-Raillard, M., Mirada cruzadas sobre la frontera México-Estados Unidos a través de la narrativa mexicana del nuevo milenio: David Toscana (El ejército iluminado, 2006) y Yuri Herrera (Trabajos del reino, 2004 y Señales que precederán al fin del mundo, 2011), Ilcea. Revue de l'Institut des langues et cultures d'Europe, Amérique, Afrique, Asie et Australia 18, 2013, pp. 1-24.

Rincones, R., La frontera México-Estados Unidos: elementos básicos para su comprensión, Araucaria: Revista Iberoamericana de filosofía, política $y$ humanidades, 11, 2004, pp. 62-70.

Sarlo, B., Sujetos y tecnologías. La novela después de la historia, Punto de vista 86, 2006, pp. 1-6.

Suárez Gómez, J. E., La literatura testimonial como representación de pasados violentos en México y Colombia, Siguiendo el corte y Guerra en el paraíso, Iberofórum. Revista de Ciencias Sociales de la Universidad Iberoamericana 11, 2011, pp. 57-82.

Suárez Gómez, J. E., La literatura testimonial como memoria de las guerras en Colombia: siguiendo el corte y 7 años secuestrado, Medellín, 2016.

Valencia, S., Capitalismo Gore, Santa Cruz de Tenerife 2010. 


\section{Alice Favaro \\ Voces efímeras: \\ el drama de la migración transfronteriza en México}

Palabras claves: migrantes, subalternidad, trata tráfico, frontera

El objeto de este estudio es la novela Las tierras arrasadas (2015), de Emiliano Monge, que relata el infierno en el que viven los migrantes centroamericanos mientras atraviesan México para llegar a los Estados Unidos de América. Mi propuesta es el análisis de la superposición de la voz de los migrantes personajes -que se intercambian constantemente con la del narrador-, de los testimonios de archivo de migrantes de América Central junto a la historia de los traficantes, a través de la ficción narrativa de la novela. Mi enfoque se centrará sobre el género ambiguo del texto, a medio camino entre el relato testimonial y la ficción narrativa y sobre el papel del sujeto subalterno dentro de la novela, víctima de los abusos de los traficantes. 


\section{Alice Favaro \\ Nepomembni glasovi: drama čezmejnih migracij v Mehiki}

Ključne besede: migranti, podrejenost, trgovina z ljudmi, meja

Članek obravnava roman Las tierras arrasadas (2015) Emiliana Mongeja, ki pripoveduje o preživljanju pekla srednjeameriških migrantov, ki prečkajo Mehiko, da bi prišli v Združene države Amerike. S svojo analizo se želim osrediščiti na glasove junakov migrantov, ki se vseskozi izmenjujejo s pripovedovalčevim, vsi skupaj pa so $\mathrm{v}$ okviru romaneskne pripovedi pričevalci zgodb srednjeameriških migrantov in preprodajalcev. Članek je usmerjen na nedorečenost zvrsti besedila, $\mathrm{v}$ katerem se prepletata pričevanje in fikcija, ter na podrejeno vlogo oseb, žrtev zlorabe preprodajalcev. 
Alice Favaro

\section{Ephemeral Voices: The Tragedy of Cross-border Migration in Mexico}

Keywords: migrants, subalternity, human trafficking, border

The analysis I propose is about Emiliano Monge's novel Las tierras arrasadas (2015). In this novel the author examines the hell in which the Central American migrants live while crossing the Mexico-United States border. I examine the multiple voices among the narrator, migrant characters, migrant testimonies and some quotes from Dante's Divine Comedy. I specifically focus on the subaltern role in the novel as a victim of traffickers abuses and the ambiguous genre of the text, between testimonial tale and narrative fiction. 